\title{
MICROSTRUCTURAL CHARACTERISATION FOR POLYCRYSTALLINE NICKEL
}

\section{Srihari Dodla ${ }^{1 *}$, Shashvat Agarwal $^{2}$, R Tejdeep Reddy ${ }^{3}$ and Saurav Sahu ${ }^{4}$}

Department of Mechanical Engineering, SRM Institute of Science and Technology, Kattankulathur-603203, India

${ }^{1}$ Email: srihariovgu@gmail.com*(Corresponding author)

${ }^{2}$ Email: agarwalshashvat@gmail.com

${ }^{3}$ Email: sauravsameersahu@gmail.com

${ }^{4}$ Email: tejdeep54321@gmail.com

\begin{abstract}
Polycrystalline Nickel has very good mechanical properties and excellent corrosion resistance. In this paper, we try to find the suitability of Nickel 200 for structural applications. The compression test on the specimens is carried out in the longitudinal and transverse directions and the difference in the strength in both the directions is studied before and after the heat treatment process. By investigation of the microstructure, the correlation between the deformation behaviour and grain morphology is investigated. The compression test results before the heat treatment reveal that by increasing the strain beyond the elastic limit, the material is anisotropic (up to $4 \%$ ). Also, the heat treatment analysis reveals that the sub-grains have occurred in the microstructure. Machining experiments have been performed on Nickel 200 to accomplish proper surface finish and dimensional accuracy. Machining results reveal that the process parameters will have a strong influence on cutting forces and surface roughness. The results showed a significant effect of the cutting speed interaction on cutting forces and surface roughness. An improvement of $38 \%$ in cutting forces was detected with increasing the cutting speed from $360 \mathrm{rpm}$ to $450 \mathrm{rpm}$ at constant feed rate $(0.12 \mathrm{~mm} / \mathrm{rev})$ and depth of cut $(0.1 \mathrm{~mm})$. However, the surface roughness was almost constant for the increase in the cutting speed.
\end{abstract}

Keywords: Deformation behaviour, grain morphology, heat treatment, polycrystalline Nickel

https://doi.org/10.47412/JLUC1902

\section{Introduction}

Nickel alloys are used in aerospace industries because of their high strength-to-weight ratio, superb corrosion resistance $[1,2,3]$. Hence this makes the machining of these materials is extremely difficult. Nickel-based alloys are known to be the most difficult-to-machine superalloys [4]. The machining of Nickel alloys with cemented carbide tools affects the tool life. In order to machine Nickel superalloys with great precision without affecting the tool life, hard machining tools are to be used. Nickel-based superalloys have elevated functioning temperature. The strength of these alloys is related not only to the chemical properties but also on the melting procedures [5].

Nickel material can be used in electrochemical industries and in MEMS (Micro Electro Mechanical Systems) applications. Hussain et al. [6] investigated the microstructure and mechanical properties of multiaxial forged Nickel 200. Song et al. [7] studied the relationship between precipitation and the mechanical properties of heat-treated welds of Ni-based superalloy (Inconel 625) after friction stir welding. In the work of Dodla et al. [8], the machinability of Nickel-based alloy (Inconel 718) has been studied by using a conventional and ultrasonic-assisted machining process. 
In the current work, the microstructural investigation and mechanical behaviour have been studied for the initial and heat treated Nickel 200. In addition, the machining experiments have been performed to accomplish proper surface finish and dimensional accuracy by varying the process parameters.

\section{Experimental Procedure}

Nickel 200 (pure wrought Nickel) is chosen as the starting material. The chemical composition of Nickel 200 is shown in Table 1. A schematic overview of the specimen in different directions in the case of microstructural investigations and mechanical testing is shown in Fig. 1 (left). Figure 1 (right) shows for machining case. Specimens of Nickel 200 are metallographically prepared for microstructural investigations [9]. The average grain size measurements were carried out using the ImageJ software [10]. Compression tests were carried out at room temperature in the longitudinal and transverse directions.

The heat treatment process is conducted in a muffle furnace with operating temperatures of $900^{\circ} \mathrm{C}-1000^{\circ} \mathrm{C}$. Nickel 200 cylindrical samples are heated to a temperature of $871^{\circ} \mathrm{C}$. Soaking time after reaching $871{ }^{\circ} \mathrm{C}$ is 700 seconds. Air cooling is done for a duration of $45 \mathrm{~min}-1$ hour. Compression tests were carried out for heat-treated samples at room temperature.

Machining experiments have been performed on a lathe machine by varying process parameters (see Table 2). Nickel 200 cylindrical specimen with a diameter of $50 \mathrm{~mm}$ has been considered. Three different force components - tangential (cutting) force, radial (thrust) force and feed force are measured using threecomponent Kistler dynamometer (Type 9257B). In order to observe the surface finish on the machined surface, the average roughness values have been measured.

Table 1: Chemical composition of Nickel 200

\begin{tabular}{|l|l|l|l|c|l|l|l|}
\hline Element & $\mathrm{Ni}$ & $\mathrm{Fe}$ & $\mathrm{Si}$ & $\mathrm{Mn}$ & $\mathrm{S}$ & $\mathrm{Cu}$ & $\mathrm{C}$ \\
\hline $\begin{array}{l}\text { Weight } \\
(\%)\end{array}$ & 99.2 & 0.12 & 0.11 & 0.21 & 0.006 & 0.08 & 0.025 \\
\hline
\end{tabular}

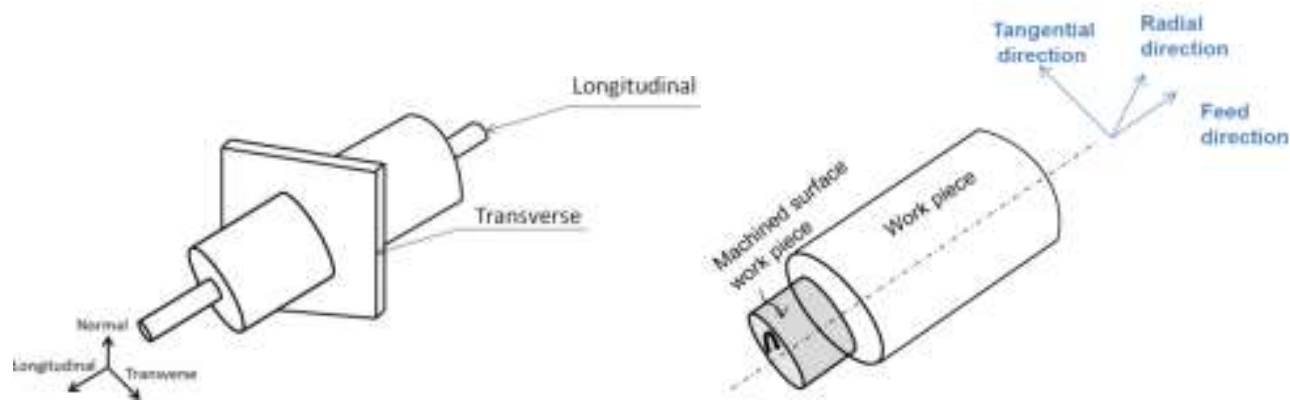

Figure 1: Schematic overview of the specimen in different directions in the case of microstructural investigations and mechanical testing (left), and in machining (right).

Table 2: Process parameters

\begin{tabular}{|l|l|l|l|}
\hline Case & $\begin{array}{l}\text { Speed, } \mathrm{N} \\
(\mathrm{rpm})\end{array}$ & $\begin{array}{l}\text { Feed,f } \\
(\mathrm{mm} / \mathrm{rev})\end{array}$ & $\begin{array}{l}\text { Depth of cut, } \mathrm{a}_{\mathrm{p}} \\
(\mathrm{mm})\end{array}$ \\
\hline 1 & 228 & 0.12 & 0.2 \\
\hline 2 & 228 & 0.16 & 0.2 \\
\hline 3 & 360 & 0.12 & 0.1 \\
\hline 4 & 450 & 0.12 & 0.1 \\
\hline
\end{tabular}




\section{Results and discussion}

\subsection{Microstructural Investigations}

Figures 2A and 2B show the optical microscope images for Nickel 200 in the transverse direction before the heat treatment. The average grain size is $50 \mu \mathrm{m}$ in the transverse direction. It is clear that the grain morphology orientation can be analysed through an optical microscope. The microstructure of heat-treated samples is shown in Fig. 2C and 2D. It is observed that the average grain size increases to $90 \mu \mathrm{m}$ with the heat treatment process. Micrograph results (Fig. 2C and 2D) reveal that the grain coarsening after the heat treatment. In addition, the microstructure images reveal that the subgrain formation inside the grains. These results confirmed that the grain coarsening after the heat treatment. Hence it is expected that the reduction in the stresses after the heat treatment.
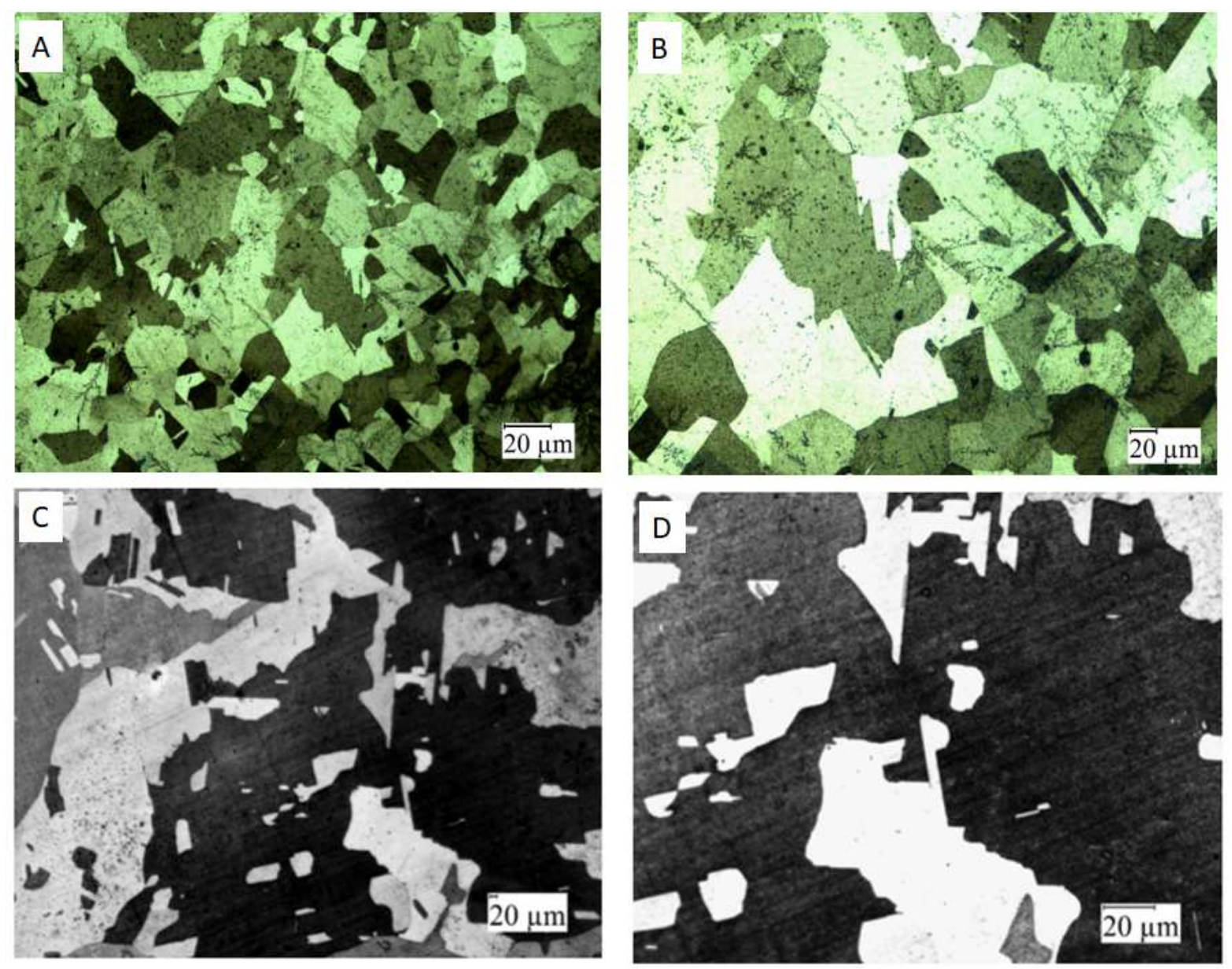

Figure 2: The microstructure of Nickel 200 in transverse directions before the heat treatment process (A and $\mathrm{B})$ and after the heat treatment process $(\mathrm{C}$ and $\mathrm{D})$

\subsection{Mechanical Behaviour}

Figure $3 \mathrm{~A}$ shows the true stress-strain behaviour from the uniaxial compression test before the heat treatment process for longitudinal and transverse directions. It is observed that the material is isotropic in the elastic region. In the case of the elasto-plastic region, there is a mechanical anisotropy in the strain range 
$1 \%$ to $4 \%$. Therefore the stress-strain curve results indicate a significant amount of difference in stress in both directions beyond the elastic limit. Figure 3B shows the true stress-strain curve after the heat treatment process. It is clear the stress-strain behaviour is isotropic and the material is isotropic after the heat treatment process. This is due to the fact that the grain coarsening and sub-grain formation after the heat treatment process (see Fig. 2C and 2D). The dislocations can run freely by a small amount of force and hence weakening of the material. With increase in the grain size in the material, the motion of dislocations inside the material has been increased. Therefore the presence of coarse grains increases the motion of dislocations resulting in a decrease in the strength of the material.
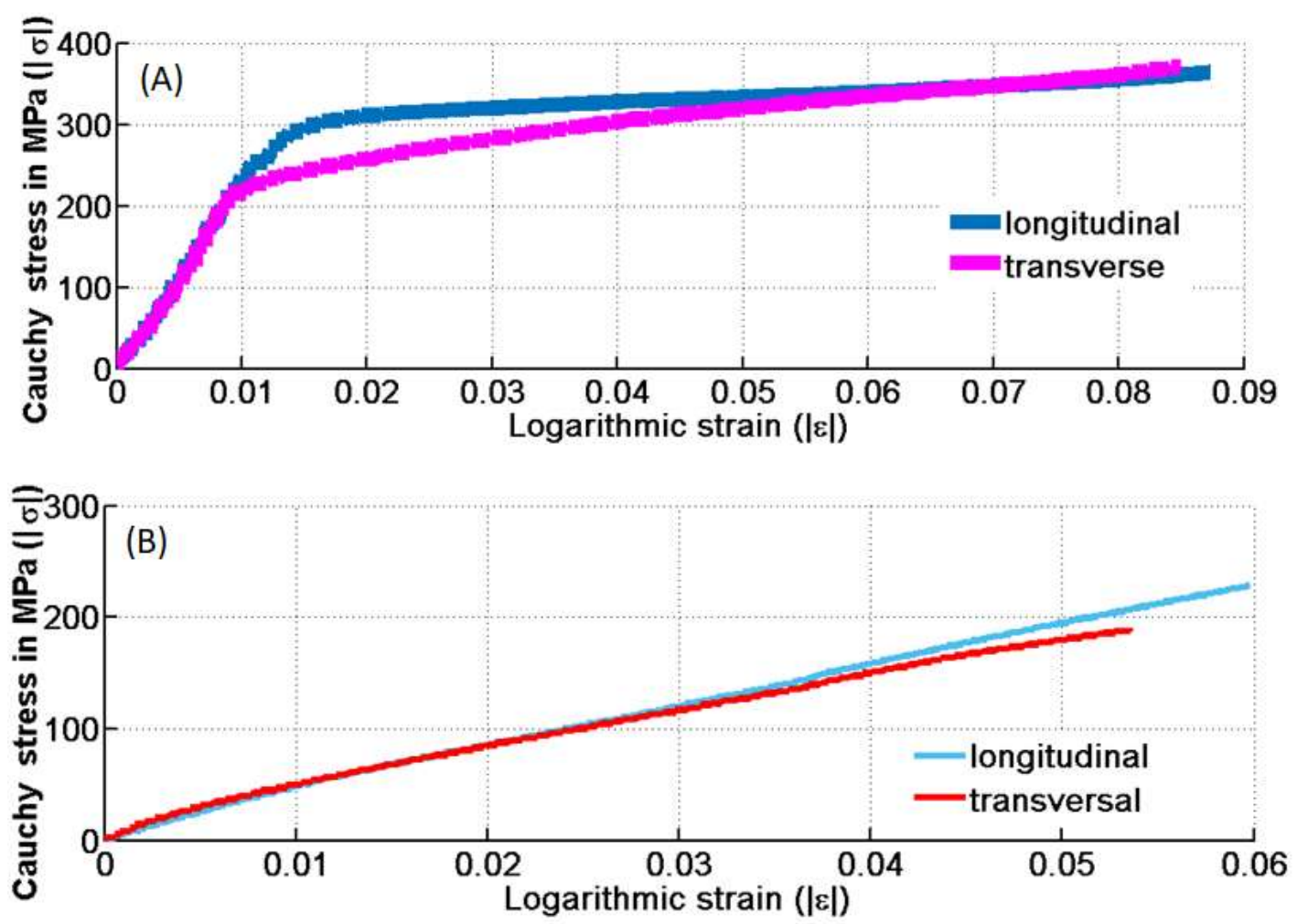

Figure 3: Stress-strain behaviour of Nickel 200 in uniaxial compression. (a) before heat treatment, (b) after heat treatment

\subsection{Machining Results}

Figure 4 reveals the typical force measurement (tangential, radial and feed components) as a function of time using the dynamometer. In the machining analysis, the raw data from the initial engagement has been eliminated (see Fig. 4). It is observed that the force components are almost constant during the cutting process. Figure 5 shows the average force components for case 1 and 2 . It is observed that force components are sensitive to the feed rate, as expected. This is because of the increase in the volume of the material removed with an increase in feed rate. Figure 6 shows the average force components by varying the cutting speed. It is observed that the forces increase with an increase in the cutting speed. An improvement of $38 \%$ in cutting forces was detected with increasing the cutting speed from $360 \mathrm{rpm}$ to $450 \mathrm{rpm}$ and keeping the feed rate and depth of cut at $0.12 \mathrm{~mm} / \mathrm{rev}$ and $0.1 \mathrm{~mm}$. This is because of an increase in vibrations of tool resulting in chartering and hence increases in forces and power consumption during machining. Machining quality can be 
assessed based on the surface roughness measurements. From Fig. 7, it is clear that the reduction in surface roughness value with increasing the feed rate and keeping the speed and depth of cut at $228 \mathrm{rpm}$ and $0.2 \mathrm{~mm}$. The surface roughness remained constant with increasing the cutting speed from $360 \mathrm{rpm}$ to $450 \mathrm{rpm}$ at constant feed rate $(0.12 \mathrm{~mm} / \mathrm{rev})$ and depth of cut $(0.1 \mathrm{~mm})$.

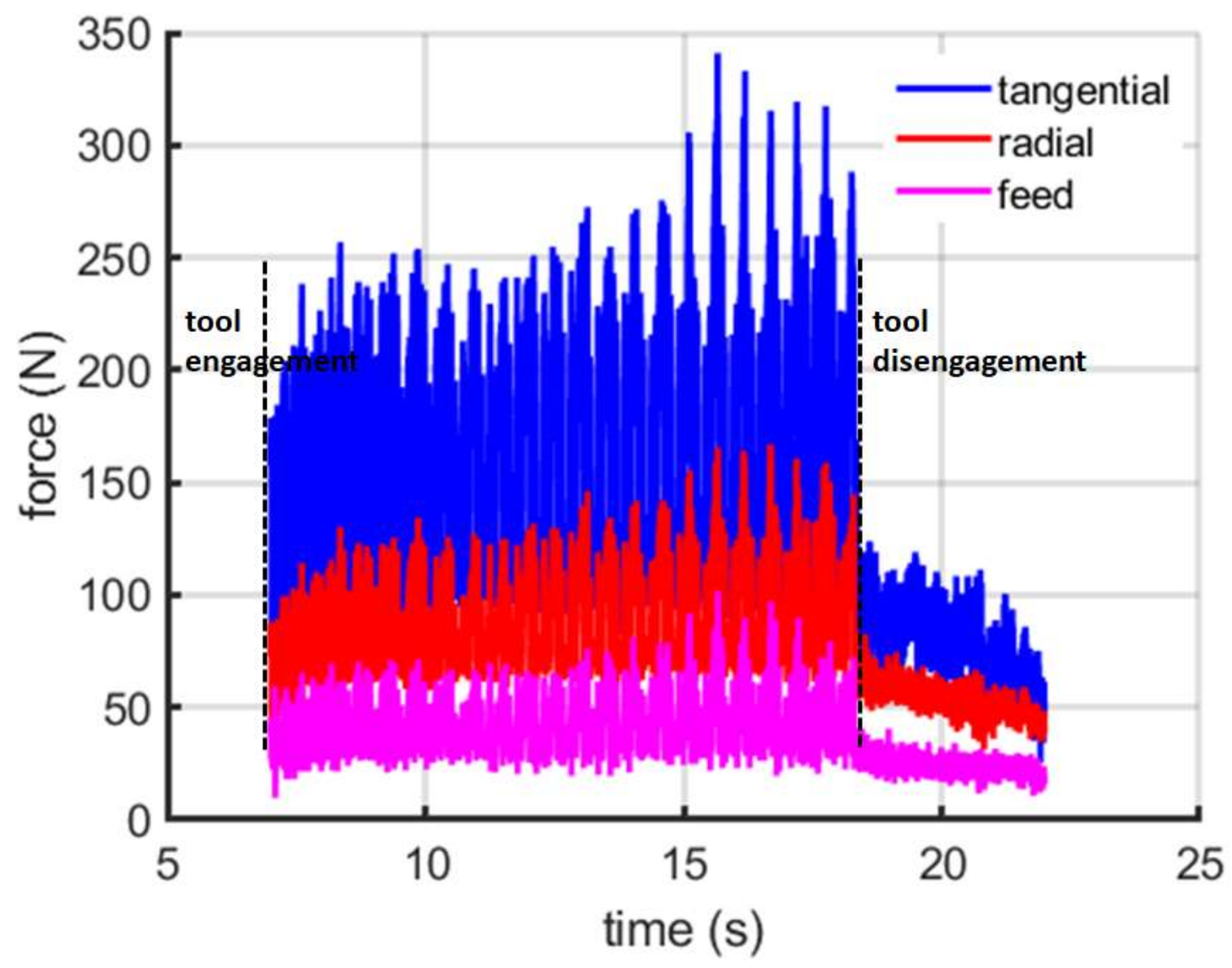

Figure 4: Evolution of machining force component signals produced by dynamometer. Process parameters used: speed $=228 \mathrm{rpm}$, feed $=0.12 \mathrm{~mm} / \mathrm{rev}$, depth of cut $=0.2 \mathrm{~mm}$
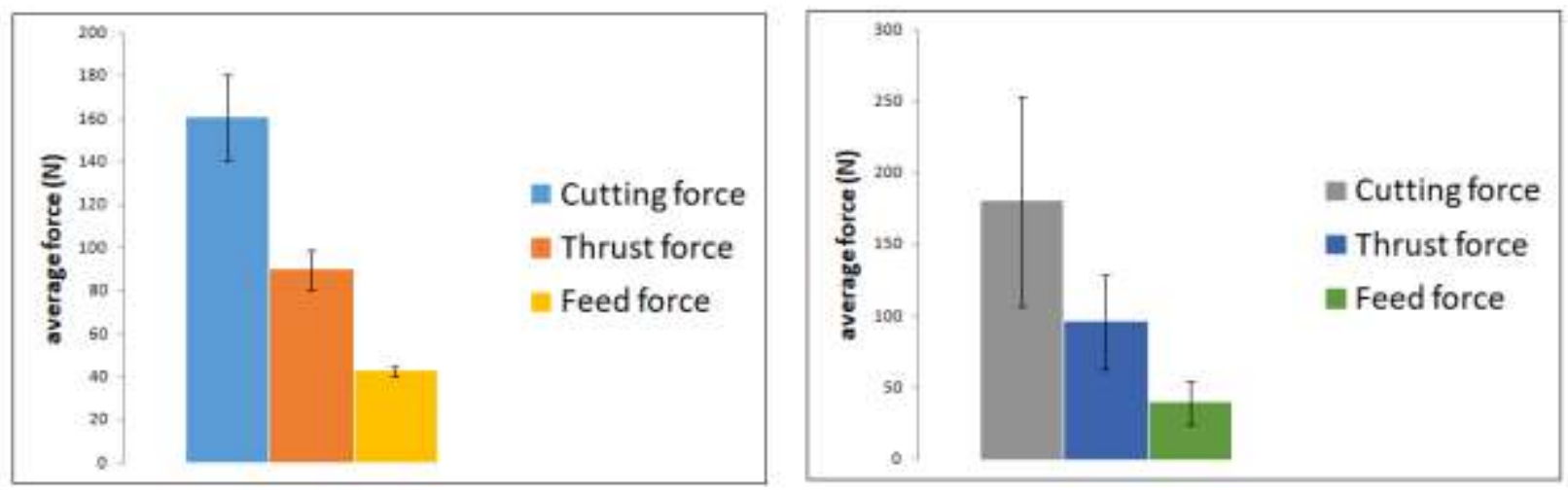
Figure 5: Average force components for process parameters(speed $=228 \mathrm{rpm}$, feed $=0.12 \mathrm{~mm} / \mathrm{rev}$ and depth of cut $=0.2 \mathrm{~mm}$ ) (left) and process parameters ( cut $=0.2 \mathrm{~mm}$ ) (right)
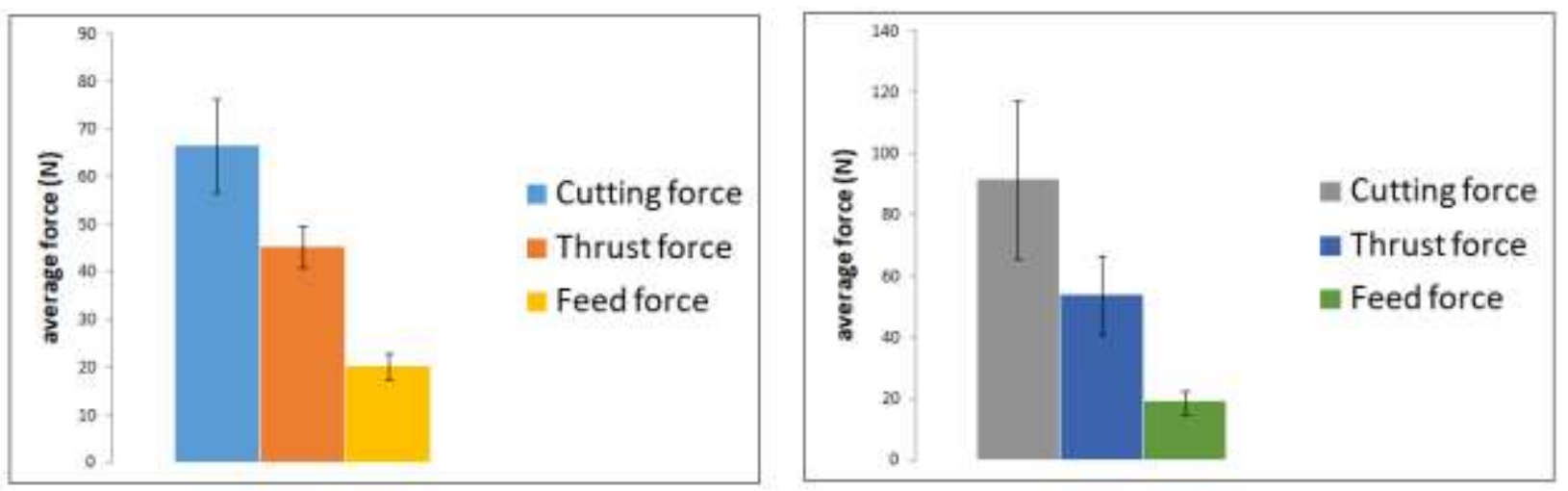

Figure 6: Average force components for process parameters (speed $=360 \mathrm{rpm}$, feed $=0.12 \mathrm{~mm} / \mathrm{rev}$ and depth of cut $=0.1 \mathrm{~mm}$ ) (left) and process parameters (speed $=450 \mathrm{rpm}$, feed $=0.12 \mathrm{~mm} / \mathrm{rev}$ and depth of cut $=0.1 \mathrm{~mm})($ right $)$

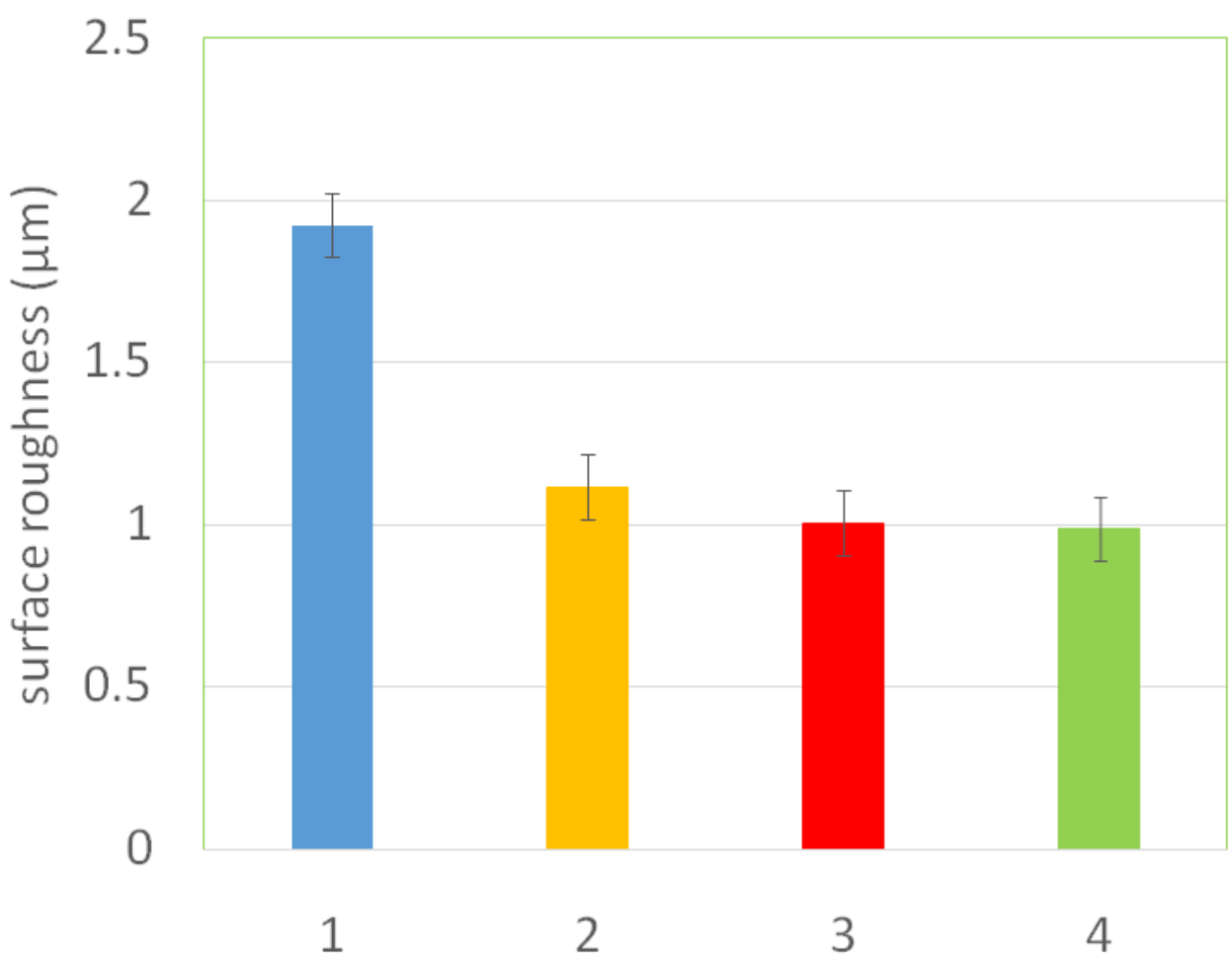

Figure 7: Surface roughness measurements for four different cases 


\section{Summary}

Characterisation of microstructure and the mechanical behaviour of Nickel 200 has been studied before and after the heat treatment process. Besides, the machining experiments have been performed on Nickel 200 to study the machining forces and surface roughness by varying the process parameters. From the microstructural investigations, it is clear that the grain size increases and the sub-grains formed after the heat treatment process. From the stress-strain behaviour, the material is anisotropic before the heat treatment process in the strain range of $1 \%$ to $4 \%$ and the material becomes isotropic after the heat treatment process. Machining experiments reveal that the cutting forces increases with increase in the cutting speed. However, the surface roughness remained constant with increasing the cutting speed.

\section{References}

[1] H. J. Wagner, A. M. Hall (1965), Physical metallurgy of alloy 718. DMIC Report 217, Battelle Memorial Institute, Columbus, Ohio.

[2] S. Dodla. Numerical investigations of flow behavior for a directionally solidified columnar Inconel 718 superalloy. Materials Today: Proceedings, (2020) (in press).

[3] Y. Zhao, T. Topping, J. F. Bingert, J. J. Thornton, A. M. Dangelewicz, Y. Li, W. Liu, Y. Zhu, Y. Zhou, and E. J. Lavernia. High tensile ductility and strength in bulk nanostructured nickel. Advanced Materials 20, (2008), 3028-3033.

[4] G. R. Thellaputta, P. S. Chandra, C. S. P. Rao. Machinability of Nickel Based Superalloys: A Review. MaterialsToday:Proceedings 4 (2A), (2017), 3712-3721.

[5] E. O. Ezugwu, Z. M. Wang, A. R. Machado. The machinability of nickel-based alloys: a review. Journal of Materials Processing Technology 86 (1-3), (1999), 1-16.

[6] Z. Hussain, F. Al-Mufadi, S. Subbarayan, O. Irfan. Microstructure and Mechanical Properties Investigation on Nanostructured Nickel 200 Alloy Using Multi-Axial Forging. Materials Science and Engineering A. 712, (2017), 772-779.

[7] K. H. Song, K. Nakata. Effect of precipitation on post-heat-treated Inconel 625 alloy after friction stir welding. Materials and Design 31 (2010), 2942-2947.

[8] S. Dodla, A. Roy, V. V. Silberschmidt 2016. Characterization of aerospace alloys: Effect of machining. In BSSM's $11^{\text {th }}$ International conference on Advances in Experimental Mechanics(pp. 1-2). BSSM.

[9] S. Dodla, P. Thiem, M. Krueger, D. Dietrich, A. Bertram. Microstructure, flow behaviour, and bulk texture evolution of cold drawn copper-silver composites, Journal of Alloys and Compounds, 647 (2015), 519-527.

[10] C.A. Schneider, W. S. Rasband, K. W. Eliceiri. NIH Image to ImageJ: 25 years of image analysis. Nature Methods, 9, (2012), 671-675. 